\title{
Bringing Tabletop Technologies to Kindergarten Children
}

\author{
Javier Marco, Eva Cerezo, Sandra \\ Baldassarri \\ Advanced Computer Graphics Group (GIGA) \\ Computer Science Department, Engineering \\ Research Institute of Aragon (I3A) \\ University of Zaragoza, Spain
}

\{javi.marco, ecerezo, sandra\}@unizar.es

\author{
Emanuela Mazzone, Janet C Read \\ Child-Computer Interaction (ChiCl) Group \\ Department of Computing \\ University of Central Lancashire, Preston, UK \\ \{emazzone, jcread\}@uclan.ac.uk
}

\begin{abstract}
Taking computer technology away from the desktop and into a more physical, manipulative space, is known that provide many benefits and is generally considered to result in a system that is easier to learn and more natural to use. This paper describes a design solution that allows kindergarten children to take the benefits of the new pedagogical possibilities that tangible interaction and tabletop technologies offer for manipulative learning. After analysis of children's cognitive and psychomotor skills, we have designed and tuned a prototype game that is suitable for children aged 3 to 4 years old. Our prototype uniquely combines low cost tangible interaction and tabletop technology with tutored learning. The design has been based on the observation of children using the technology, letting them freely play with the application during three play sessions. These observational sessions informed the design decisions for the game whilst also confirming the children's enjoyment of the prototype.
\end{abstract}

\section{Categories and Subject Descriptors}

H.5.2 [User Interfaces]: Interaction Styles, Input Devices and Strategies.

H.1.2 [User/Machine systems]: Human Factors

\section{General Terms}

Design, Experimentation, Human Factors.

\section{Keywords}

Tangible, Children, Tabletop, User Center Design, Input Devices, Interaction Design, Autonomous Agents, Game, Learning, Augmented reality.

\section{INTRODUCTION}

In recent years there has been a significant rise in interest in the design of interactive technologies that move away from the traditional GUI desktop into the spaces and places that people more naturally inhabit. These innovations have included large

(C) The Author 2009.

Published by the British Computer Society screen displays, tabletop computing and ubiquitous systems. As the technology has changed there has been a need to design and implement new input technologies and new modes of interaction. Much of this work has been done in the subdomains of tangible computing and tabletop interaction where the emphasis is on interactions that do not require any learning process from the user, nor the use of unnatural hardware gadgets. Wellner's pioneering digital desktop application [32], together with the Ishii and Ullmer tangible bits innovation [17] are the starting point of TUI (Tangible User Interfaces) on tabletop applications.

Nowadays, the new technologies based on tangible and tabletop applications are making computer applications more accessible to more diverse set of users than before. These include users with physical or psychological disabilities, elderly people, or pre-school children. This latter group is the base of the research of this paper.

The educational and ludic possibilities offered by the combination of tangible and tabletop technologies for children have been reported in [34]. It is clear that these physical technologies are well suited to children, especially if they are designed to include aspects that are relevant to the child's development: social experiences, expressive tools and control [12]. Tangible and tabletop applications for children can give them benefits, not only for fun, but also from an educational aspect and, if designed optimally, they can help children in their motor-skill and cognitive development.

The remainder of this paper is structured as follows. In the next section the background research on which this paper is based will be showed. Section 3 presents the general characteristics of the technology system. Section 4 is devoted to analysis of the pedagogical and psychomotor issues that related to our specific user group. Section 5 described the platform and underlying hardware together with the interactive capabilities of the tabletop used in the initial game prototype. The evaluations of this early prototype with children are described in section 6 and how these conducted the adjustments that were made to the game. Finally, the authors draw some conclusions and suggest next possible stages for the work.

\section{BACKGROUND}

Several works have been references for the design decisions taken on the prototype showed in this paper. Grouped by the technology they have used:

\subsection{Physical and Tangible Toys for Children}

Working on TUI applications for children using physical toys as tangible bits, electronics have to be added to the toys, turning them into digitally interactive devices. Augmenting the toys in 
this way gives many benefits. They retain its physical properties and they are not bound by any restrictive rules or limitations on its use. The toys can be freely used and their function is creativity and emotion expression. Augmenting the toy with technologies adds new possibilities and can improve the child's creativity and imagination. As an example, the I/O Brush [28], a toy brush, with video-camera hidden in the brushes, leaves no doubt about the way it is used, and brings unlimited creativity possibilities to children who can paint, with different textures on a large video-screen.

Equipped with sensors, physical toys are showing their potential in physical storytelling applications suitable for kindergarten children [13]. An example of work that employs augmented toys in this context is "Swamped!" [18], a 3D storytelling game where electronic sensors transform a simple stuffed chicken, into a sympathetic playful interface. Similarly, Story Toy [14] lets the children play with linear and branched narrations on a toy farm with electronic sensors making use of voice but not of images. In cooperative storytelling, POGO world [27] proposes a physical technological enriched environment where multiple children collaborate and interact with each other to narrate their own stories, using verbal, but also through the physical manipulation of photos and audiovisual material. Combining all this benefits, Cassell and Ryokai [9], with their StoryMat interactive storytelling space, succeeded in involving pre-school children in physical manipulative and collaborative storytelling fantasy adventures.

\subsection{Tabletop Interfaces for Children}

Other applications for children are based on tabletop interfaces with multitouch interaction. Tabletop applications mainly implement classical games, like jigsaw and board games, by combining them with tabletop technologies. These are the case of the Smart Jigsaw Puzzle Assistant [6] and the False Prophets [21], respectively. These games are usually designed for ludic purposes, mainly oriented to general audiences. In the educational side, Ticle tabletop [29] explored collaborative educational games that support teaches in transmitting mathematical concepts.

Other works focus on exploring the social benefits of collaborative tabletop games for children who have special needs. As an example, the SIDE Project [26] aims to improve the social skills of adolescents with Asperger's Syndrome.

Possibly because tabletop interaction requires fine muscle coordination, which is usually achieved when the child is around seven years old, there are few tabletop applications for very small children. Mansor et al. [22] evaluated a DiamondTouch Tabletop game by comparing a physical dolls house, with a virtual reconstruction in the tabletop. In this study, evaluations with children between 3 and 4 years old showed many difficulties with the interaction including frustration by the child when playing with the tabletop game when the system didn't respond to their "little finger" interaction. To achieve a tabletop application suitable for young children it appears that a careful study needs to be made of children's abilities - this can be effected by observing children's interactions with playing with physical toys on table surfaces.

\subsection{Tutors: Embodied Agents for Children}

One of the earliest promises of computer technology was that it would replace the teacher and become a tutoring device for users. Initially relying on the programming of multiple responses to questions, tutoring applications for computers are now using artificial intelligence and stochastic modeling to provide multiple and variable responses within highly interactive systems. Nowadays, virtual tutors in educational applications are oriented to reinforce knowledge and give motivation, whilst often complementing the work of the human teacher.

The use of embodied agents that take the role of tutors in educational applications [19] has been lauded as being an adjunct to normal learning. The reinforcements offered by the agents of the transmission of information to the learners in educative applications. This effectiveness is due to, among other things, the emotional or affective capabilities of the agent [5]. These autonomous pedagogical agents are mainly found in applications for adults and are less often seen in applications for very young children. The SAGE (Storytelling Agent Generation Environment) project [4] is one example that does apply to young children; this proposes a physical storytelling implementation with stuffed animals and verbal interaction, which allows children to explore their own identity.

\subsection{Designing Useful Technology}

As it can be seen, the combination of tangible technologies for input and a tabletop setting for interaction is not unusual but in many cases the resulting application is either rather static or uninteresting or is so complex to install that it cannot be played anywhere except in the laboratory where it was conceived or it is not suited to young children.

The design prototype described in this paper goes beyond these common tabletop constraints by adding agent technology (to improve the play), a low cost easy to implement hardware configuration and proposes a storytelling application for children aged $3-4$ years old which was designed whilst taking careful consideration of the development stages of children. Specifically, this tabletop design is focused on children learning together whilst manipulating toys that are inherently fun. Along this paper, we will describe our observations of children playing with this tabletop, and how we used the collected information to progressively design an interactive Farm Game for these very young users of technologies.

\section{BRINGING TOGETHER TANGIBLES,} TABLES, TUTORS

The work presented here is part of a larger study that aims to exploit the potential of tangible user interfaces (TUI) for young children's development. The application we propose is a tabletop prototype for children aged $3-4$ years old with a storytelling game that has an autonomous pedagogical agent for guiding the child. This application was achieved by implementing a tangible system through the adequate adaptation of existing technology rather than developing innovative tangible technologies.

The main points by which this research is different from previous works are:

- The emphasis on toy manipulation. The prototype is implemented as a tabletop, but interaction with the game is based on toy manipulation (provided by fiducials). Thanks to this, children can benefit in their motor skill development as it is explained in the "Pedagogical Issues" section.

- The design of the underlying platform focuses on robustness and simplicity in a hardware configuration that does not require high cost technology. The result is a low cost tabletop design, portable, easily installable and replicable, suitable for using in schools, or children's homes. A detailed description of tabletop is given in the "Tabletop prototype" section. 
- The combination of tangible interaction and Embodied Conversational Agents (ECAs). This enhances pedagogical communication in the games and pedagogical applications developed for this tabletop.

- The involvement of children (user contribution) during the design process: in the tabletop creation and in the game implementation. So that, the tabletop has evolved and adapted, enriching children experience with the games. Observing children playing with this, has been decisive on selecting the game paradigm, as is shown in "The Design of the Game" section.

The work presented in this paper attends to the three research areas of: tabletop, tangibles, and autonomous agents. The present prototype is intended for kindergarten children, and the implemented game is based on the storytelling paradigm.

\section{PEDAGOGICAL ISSUES}

The design of new interactive tools for children depends on a thorough analysis of the characteristics of children's cognitive skills development so that suitable games can be designed and this design can benefit the overall cognitive and physical development of the child. In this section, the potentials of the use of the technologies exposed in the previous section are examined against relevant theories.

\subsection{Psychomotor Skills and Cognitive Development for Tangible Interaction}

According to Piaget's theory [25], children between 3 and 4 years are in the preoperational stage in which they begin to develop the symbolic function (language, symbolic games, mental image, imitations). Around this age, visual-manual coordination and perception appear and begin to consolidate. For example, children look at what they paint and then try to control the movements of their hands. Also, at this age, children show more interest and attention for their works and they begin to consider the limits of space; when drawing, they realize they need to stay inside the sheet of paper. Between 3 and 6 yearsold, children are in the gross skills development stage (wide movements, general and visual-motor coordination, muscular tone, balance...) and it is only later on (around 7) that children begin to acquire fine motor skills (fine and precise movements, phonetics) [15]. Figure 1 represents these concepts.

With regards to the cognitive development, most educative game activities for children between 3 and 6 years focus on the development of the emotional level. In this perspective, activities are oriented to help children to improve their relationships with themselves and with others, using objects as an important element of support in communication. Children investigate the properties and behavior of objects: acting and establishing relationships with the physical elements, exploring and identifying them, recognizing what effects they produce, detecting similarities and differences, and then comparing and quantifying and so on. In this way, the child goes from manipulation to representation. This is the origin of the incipient logical and mathematical skills [Gesell 1997]. Once the body information is automated, children begin to accede to the symbolic level, and, gradually, they can form mental pictures of things, beings and objects, and can assign them different meanings.

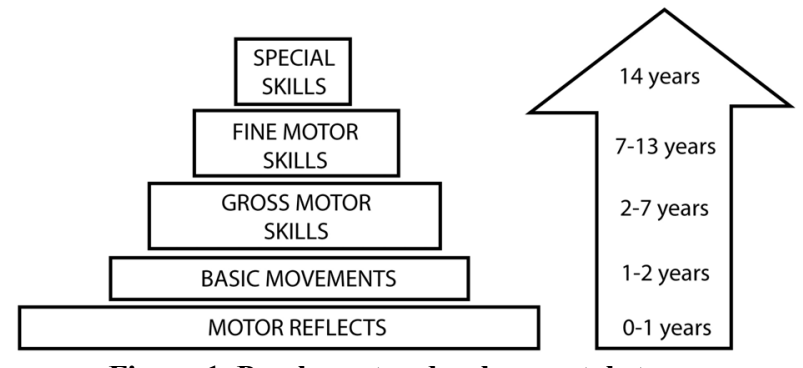

Figure 1. Psychomotor developmental stages

[Gallahue 1989].

The pedagogical values of object manipulation have been promoted by María Montessori [7]: "Children build their mental image of the world, through the action and motor responses; and, with physical handling, they become conscious of reality". The physical handling of materials is also seen as beneficial by Alibali and DiRusso [1] who came to the conclusion that children can better solve problems handling materials than they can the same problem with only pictures. Chao et al [10] called this concept the "tool of mental sight".

In this context, tangible technologies give children more freedom for exploring, handling and thinking about object properties and their possible effects in the digital world. When combined with learning, these digital manipulative elements are thought to provide different kinds of opportunities for improving the child's reasoning about the world, by means of examination, exploration and participation [30] [31]. Tangible applications also allow children to combine the known and familiar things with unknown forms, encouraging creativity and reflection.

\subsection{Tutored Learning}

At the beginning of the 20th century, Lev Vigostky [33] investigated children's games from the perspective of psychological phenomena and examined their role in the child's development. He defined the "zone of proximal development" as the distance between the actual developmental level (determined by independent problem solving by child's knowledge) and the level of potential development (determined through problem solving under guidance, or in collaboration with more capable peers). In this way it is claimed that the inclusion of virtual tutors or agents in games favors children to achieve their zone of proximal development, improving their learning in things they could not do alone. During gameplay, the pedagogical agents increase the user's motivation since there is an "entity" that takes care about their progress [11].

\section{NIKVISION DESCRIPTION}

The first stage in this research was to build a platform on which games could be layered. This platform had five main components - the hardware configuration, the visual recognition application, the $3 \mathrm{D}$ engine software, the Agent technology and the design of the Interaction. These components are described in detail in the following sections.

\subsection{Hardware Configuration}

On designing the prototype, the most important factors were: low-cost, technologically simple, easily installable, easily dismountable to transport, and versatile in lighting conditions. As the prototype would be mainly used by small children, it also needs to be robust, safe, and suitable in size.

The computational process resides on a standard PC computer with Windows XP with the following input-output connections: 
- Inputs: USB video camera and microphone.

- Outputs: television screen (video) and speakers (audio).

The tabletop (or playing surface) consists of a table sized $70 \mathrm{~cm}$ $\mathrm{x} 70 \mathrm{~cm}$, and $45 \mathrm{~cm}$ in height (see figure 2).
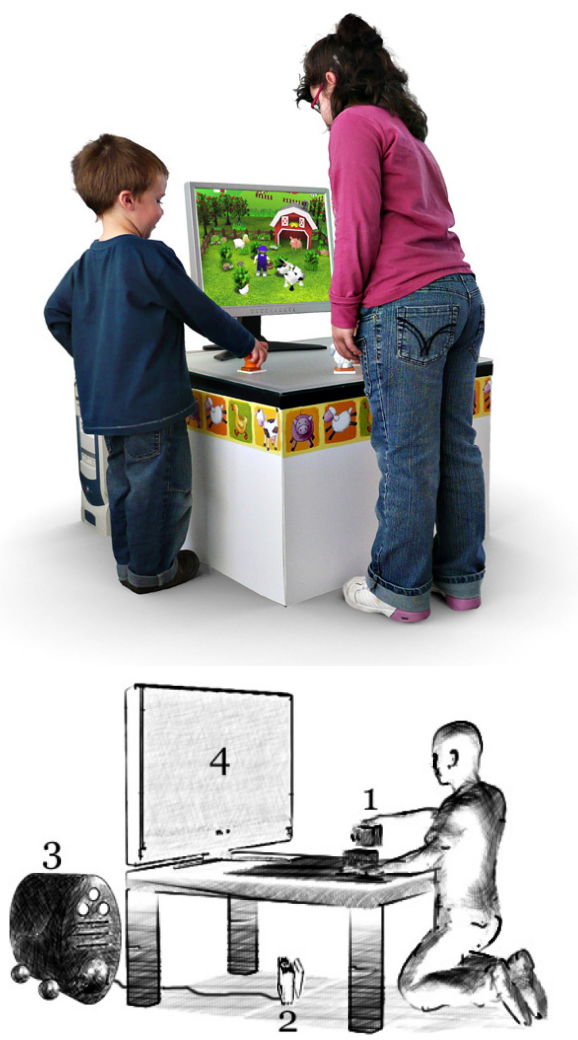

Figure 2. Tangible Tabletop prototype.

\section{Tangible objects manipulated by user. 2. USB video} camera. 3. PC computer. 4 . TV set with speakers.

The table surface is made of translucent material and a USB video camera is located under the table in order to read the toys the child places and manipulates on the table. Unlike other tabletop configurations, this design does not show a computational image on the tabletop surface, but on a monitor disposed in front of the child. As we are not projecting image onto the table, we can work with visible, rather than infrared, light. This reduces the cost, and allows the use of a wide variety of high quality cameras and lighting devices. The tabletop is made of diffuse translucent material, so that the camera only sees what is directly on the table, reducing the influence of external lighting conditions.

The resulting tabletop configuration is simple enough to be easily replicable and reconfigurable in different sizes and shapes. Moreover, a tabletop design like this can easily be installed in kindergartens, schools, museums, and any place it was intended to be evaluated. In addition, a wide variety of other tangible tabletop applications can be easily implemented for playing on this tabletop surface.

\subsection{Visual Recognition}

The children play with wooden, plastic, or rubber toys that don't need any modifications to store electronics or active devices as all the information that is captured by the camera is visual. A black\&white printed fiducial ${ }^{1}$ is attached to the base of the toy so the recognition software is able to identify each toy as it is placed on the table (see Figure 3) [Mallik 2002].

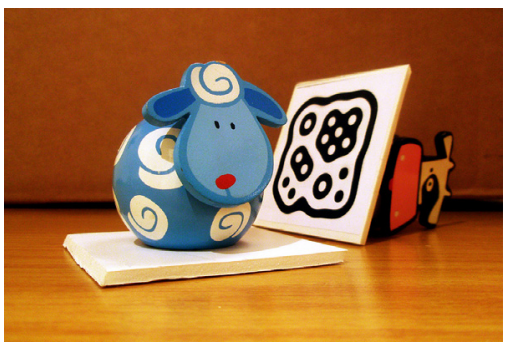

Figure 3. Wooden toys with fiducials attached to their base.

Reactivision [3] software is used for fiducial tracking because of its robustness and good performance. The Reactivision marks can be printed on cardboard and are robust enough to resist even some occlusion in the fiducial. Each mark is different from the other and each has an ID number univocally associated. Reactivision can track an almost unlimited number of fiducials using a standard web-cam, retrieving position, orientation and the ID number of any fiducials that are within view of the camera. In our tabletop, Reactivision software is continuously monitoring video camera signal, and tracking the fiducials directly placed on the table, and is then sending this data to the game through TCP-IP packets.

\subsection{The 3D Game Virtual Scenery}

The objects that are tracked on the tabletop are represented on a $3 \mathrm{D}$ virtual environment that is shown on the monitor. This environment is implemented with Maxine software [2] which is a $3 \mathrm{D}$ engine for the management of virtual environments and virtual characters in real time. In Maxine it is possible to load geometrical models, animations, textures, videos or sounds as they are required in the virtual representation. Maxine is written in $\mathrm{C}++$ and employs a set of open source libraries, like the following, among others:

- OpenSceneGraph [24] for 3D visualization,

- CAL3D [8] for skeletal animation,

- OpenAL++ [23] to handle 3D sound.

It is especially oriented to the management of $3 \mathrm{D}$ interactive characters. The communication between the image recognition software and Maxine is made via TCP-IP. Therefore, the two processes can be split into different computers, achieving scalability and allowing the system to handle more than one video camera which is an advantage for bigger installations.

\subsection{Pedagogical Agents}

Even though Maxine is a very generic engine, it has been specially oriented to work with virtual characters. It implements body and facial animation, lip-sync, and allows the character to show emotions through facial expressions and voice. In Maxine, virtual agents are endowed with the following differentiating features:

- They can be modeled and animated using commercial 3D design applications so that it is very easy to include and manage any character in the different applications.

- They support interaction with the user through different channels: text, voice (through natural language), webcam,

1 Fiducial: visual printed pattern which has topological characteristics that make the fiducial easy to detect and track by visual recognition algorithms. 
peripherals (mouse, keyboard, joystick), which makes the use of the generated applications available to a wide range of users (in terms of communication ability, age, etc).

- They have their own emotional state, which may vary depending on the relationship with the user and which modulates the agent's facial expressions, answers and voice.

Maxine agents can act as virtual tutors or virtual companions that help children in their learning process, proposing new activities depending on the children characteristics and evolution.

\subsection{Tangible Interaction}

The tangible interaction is achieved by manipulating the tangible toys. During play, the children move the toys over the translucent surface of the table, putting their base on contact with the table to enable the camera to see the markers located under that base. The user can interact with the toys in the following ways:

- Move over the surface (see figure 4): Children can grab the toys and drag them over the surface. The software tracks the position and velocity of the toy over the table and this is reflected in the game.

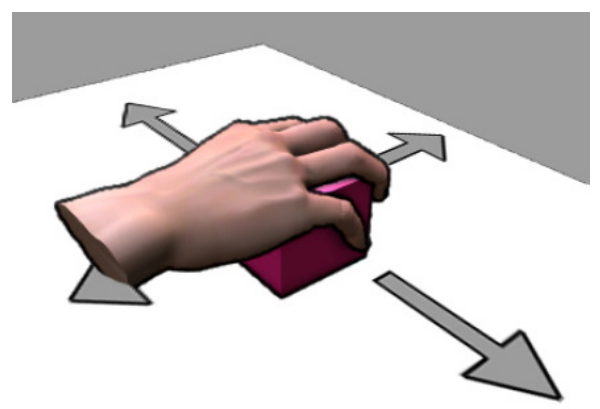

Figure 4. Drag toy over the desktop.

- Rotate toy (see figure 5): The toy can be rotated on the desktop and so long as the base with the marker remains on the table the software can track this orientation. Thus, toys that have a distinguishable front and back can be oriented by the child during the play in the game; e.g. a toy car is moved and oriented on the tabletop and a virtual $3 \mathrm{D}$ car on the monitor will move and orient the same way in the game.

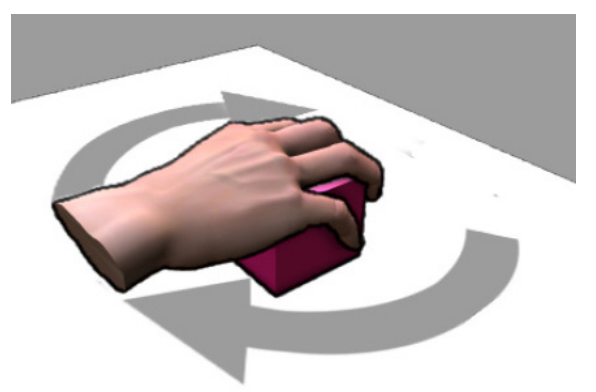

Figure 5. Rotate toy.

- Hit toy (see figure 6): Children can grab the toy and "lift and hit" it on the surface (take a little jump with the toy). The visual software cannot track the toy when it isn't placed on the surface, but it can detect that the toy has been removed from the table during a short time and the software is programmed to interpret this as a "toy click" (in analogy with "mouse click"). Game applications of this event will be explained later on this paper.

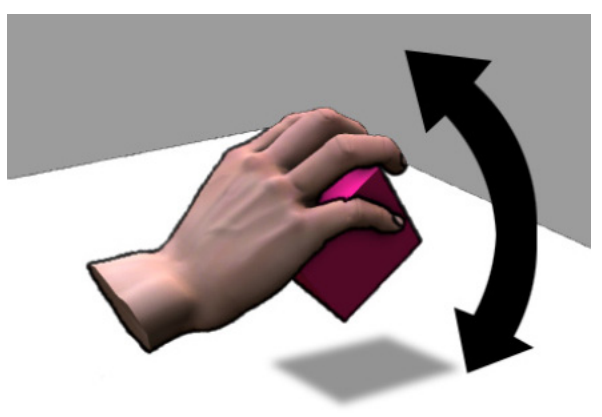

Figure 6. "Toy click"

There is no limit on the number of toys that can be placed and moved over the desktop (as long as there is free space on the table) (see figure 7). This enables more than one child to play on the desktop at the same time, and opens the application space to social activities.

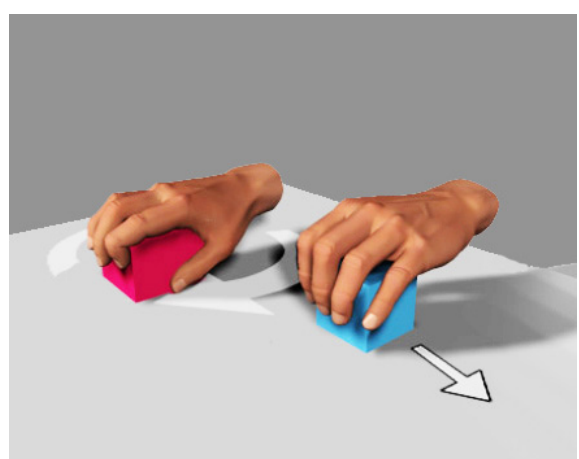

Figure 7. Multiple interactions at a time.

The design of these key toy interactions were based on observations of children playing with their usual toys (cars, rubber animals, wooden cubes...) over surfaces.

The objective is to implement tabletop interactive games where children gives inputs to the digital system the same way they create their stories during their usual play time with their toys. The result has been the farm storytelling game described next.

\subsection{Designing the Farm Game}

Once we had the technology working we needed to define the structure of a game suitable for the selected age range. We had different settings for games using this technology and we decided to focus on the farm setting. This consisted of a virtual farm with a farmer as a virtual agent shown in the screen (see figure 8). The farm animals were a few plastic animal toys with fiducials attached on their bases and these were made available on the tabletop for the children to play with (see figure 9).

The idea behind the game is to let the children play freely with the animals all over the meadow (tabletop). These are represented on the screen as fully animated characters. On the screen the animals walk and make sounds when children drag them around the tabletop. 


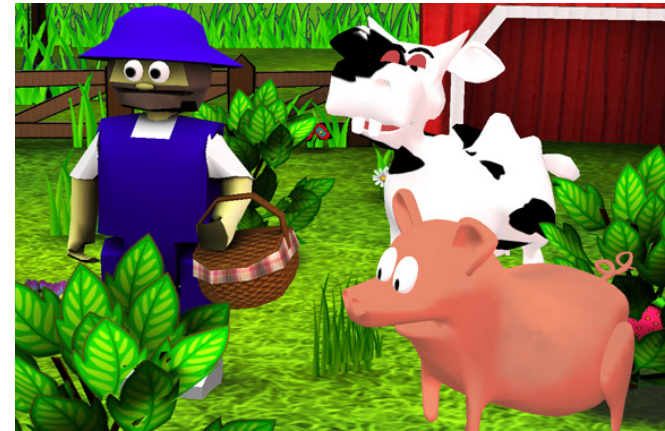

Figure 8. Virtual Farm.

Each animal is the virtual representation of a tangible toy.

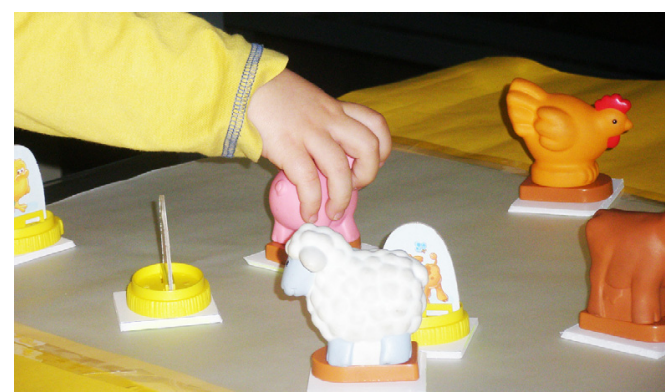

Figure 9. Toys in the farm game.

\section{INCLUDING CHILDREN IN THE DESIGN PROCESS}

We had always wanted to have a user-centered approach to the work and so it was essential to consider children's contributions. As suggested by Druin [12], children's roles can move from being final users to equal partners. In between these two extremes they can shift from prototypes evaluators to critical informants at different stages of the process. Given their young age, in this study children acted mainly as users, but they were observed in play in a very early developmental stage of the prototype and thus informed the future designs. In this way the few short trials that have been run have had the main aim of triggering the content development of the game and at the same time uncovering any major usability faults.

At the beginning, we implemented a very basic farm game with just a few animal toys (chicken, cow and sheep), to start seeing how children play with the virtual 3D farm with an autonomous farmer who proposes simple activities.

\subsection{Three Free Play Sessions}

In line with this approach and having only a general idea of the game, we arranged three individual free play sessions in a time span of three weeks with three children aged 3 to 4 . We let each child play freely in the setting to understand the real potential and limitations of the game. Between one session and the next, small improvements were added to the game according to the interaction the previous children had had. The play was observed by the designer involved in the development and another researcher who was in charge of taking notes of the children's interaction with the game by paying particular attention to the children's behaviors and reactions while playing. The sessions were video-recorded so that they could also be shared with researchers who did not attend the tests. Two cameras were used, one oriented to the child, and the other oriented to the screen, so that detailed information of the real and virtual world could later be observed in a post-produced split-screen video (see figure 10)

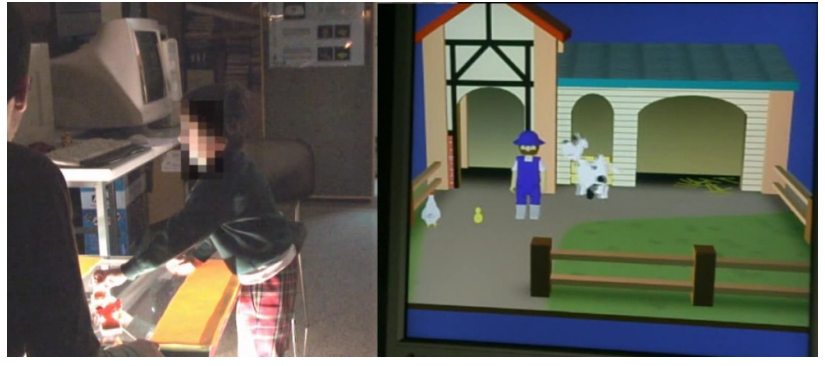

Figure 10. Split-screen video with real and virtual farm.

The sessions were intentionally unstructured and planned in a short time interval as their aim was to give to the developers a specific idea about the way children would behave in such a setting and what type of interactions would be most suitable for them.

\subsection{Findings from the Play Sessions}

Being the first time that the children played with the table top, they all showed a high acceptance and fun, asking for more time to play or more games to test.

The first session uncovered issues that had mainly to do with the physical arrangement of the technology like the lighting and the safety of the position of the hardware below the table. The child sometimes hit the lights or the camera with his/her feet, and he/she has to stop playing in order to readjust the components.

When children handled the interactive objects, their psychomotor skills limited the precision of the movement. This was subsequently taken into account when designing the dimensions of the sensitive areas in the space allowing more flexibility. Some actions need the toy animal to be oriented to the object it has to interact with. This action needs to be quite relaxed, as it was observed that children of this age take some time to manage the concept of orientation; it was noted that with a little practice, the children succeeded in correctly orientating the toy.

The setting of the game forces children to continuously look at the screen to find the response to their actions. At the same time they also have to look at the table and the objects they want to play with. As some of the objects had specific sounds associated to their proper actions in particular places, it was noted that this helped the child in understanding positive feedback to their action even when not looking at the monitor. This observation indicated that it would be good to implement a wider variety of interactions amongst the elements and to differentiate them with specific sounds as these did not require a change in focal attention. Based on the same principle, it was also decided to facilitate the correspondence between the actions on the tabletop and the events in the virtual space by clearly marking, in a visual way, key elements on the hot spots of surface of the table where the actions are programmed to take place (see figure 11).

With these implementations in place, the second child had the chance to play with a more interactive game and the evaluation was able to focus more on the playful aspect of the game rather than on the technical aspects. For this second evaluation new animals and interactive activities were added. 


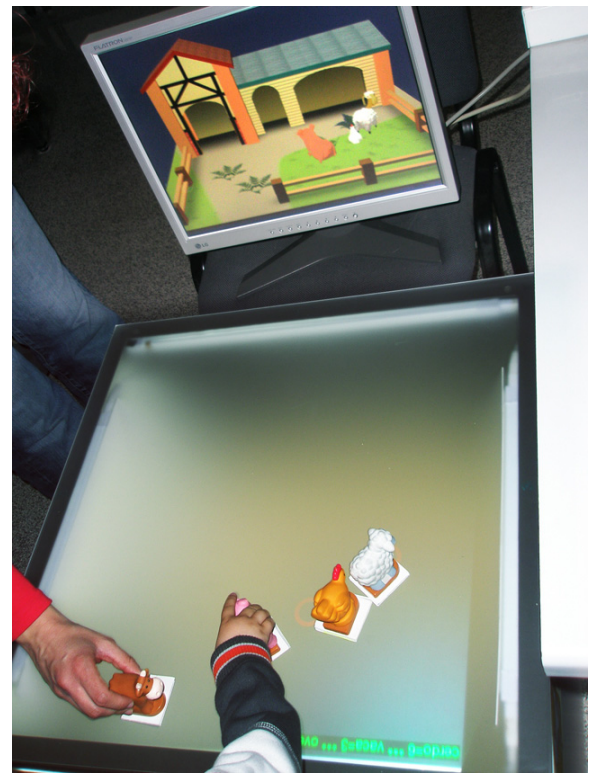

Figure 11. Interactive zones can be drawn on the light difusing surface.

The introduction of new elements highlighted some problems with the interpretation of some of the movements the children made with the elements; for instance, this child lifted the object and simulating the animal jumping. So that this was not interpreted by the machine as a temporary disappearance of the object, we attached digital meaning to this gesture with additional interactions, called the "toy click" (see hardware description at section 5.1). To highlight the happening of these events we decided to add objects the animals can interact with this specific gesture, like a bucket for the cow to store the milk and a nest for the chicken to lay eggs in. The "toy click" was successfully tested in the third session.

The three sessions resulted in the design of a structured version of the game according to the technology potential and the user ability. The following section is going to describe the current version of the game.

\subsection{The result: Interactive Farm Game}

Using the technology described in the previous sections and with corrections based on the observations described, we finished the design of Farm Game. It is proposed as an activity center where children trigger different activities by manipulating toys on the tabletop as described above.

The tangible toys are made of wood, plastic, and rubber; the animals are: a pig and her piglet, a sheep and her little sheep, a cow and her calf, and a chicken and her chick. In addition there are some toy farm tools, such as a little bucket, to play with.

Children play freely with the animals on the tabletop, creating their story in the farm. 3D animals get animated on the virtual meadow; they walk when children drag them, and "talk" to each other when placed facing each other.

The autonomous farmer agent prompts the children to play when he detects inactivity on the tabletop, currently he proposes the child to do the following activities:

- Feeding the animals: each animal has a place to eat. The farmer explains the necessity of feeding the animals and asks the child to place the animal where the specific food is (fodder, barn, grass, etc). The child has to drag and correctly orient the animal. The different spaces, or hotspots, where the animal can eat are drawn on the surface of the table in correspondence to their equivalent on screen. That helps the children locate the different interactive spaces of the farm. Sometimes, the food runs out and the animals ask for more. The child then has to drag the animal to the virtual farmer to ask him for food.

- Specific animal interactive activities. The chicken has a nest where she can lay eggs. A nest is drawn in the table surface in correspondence to the 3D nest on the screen. If the child put the chicken in that place of the table, the chicken sits in her nest. If the child does the "toy click" movement (as described in the previous section) with the chicken in the nest, the chicken lays one egg (see figure 12). The virtual farmer can propose the egg activity at any moment, asking for a specific number of eggs. When the task is finished, the farmer walks to the nest and picks the eggs up, thanking the child. A similar activity can be done with the cow, which gives milk. There is a physical toy bucket that the child has to place near the cow. If he/she lifts the cow (the "toy click" action) in that place, the cow drops some milk in the virtual bucket. When the bucket is full, the farmer goes to pick the milk and empties the bucket to play again.

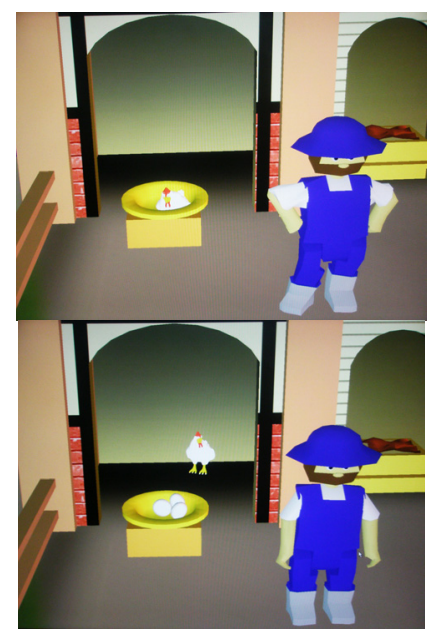

Figure 12. Chicken puts eggs with the "toy click".

- Baby animals: another activity the farmer is in charge of has to do with looking after baby animals to be sure that the young animals are always near their mothers. If a little one is alone for too long, the farmer asks the child to bring it next to its mother.

\section{CONCLUSIONS}

A tangible tabletop tutoring prototype suitable for children has been designed and tuned. Our tabletop hardware design is, at the same time, simple and robust and whilst also being a versatile tool for fast prototyping of tabletop games and new hardware tangible innovations.

A Farm Game oriented to children, has been also implemented and evaluated during three free play sessions with children. The observation of children playing was a great source of ideas to tune and correct the initial implementations and to develop new ones. The tests performed have shown children acceptance and fun, but also have highlighted problems that should be taken into account in further developments, as will be explained in the future work section. An intrinsic limitation is, of course, the question of the restriction to play on the table surface. Nevertheless, this restriction is quickly assumed by the children and makes the system robust and reusable.

Moreover, observing the kids playing and having fun with the game has been motivating and a source of new ideas to improve it. 


\section{FUTURE WORK}

At present time, and thanks to the decisions taken during the design process of the game, a reliable performance of the tabletop technology and a structured experience for the children playing the farm game have been achieved.

The farm game is now ready for implementation as a complete storytelling game. The scripting work has started and this is being carried out with additional input from pedagogical experts and professional storytellers. It is designed as a complete story with the farm animals with $3 \mathrm{D}$ graphics and audiovisual language that is similar to the cartoons that children are used to seeing on the TV, but has the additional interactive actions on the tabletop and incorporates the physical toys. The storytelling game is divided into some cinematic (non interactive) scenes, where the situation with the animals and the farmer is explained to the children in a theatrical way, and also into the interactive minigames, where children have to solve the situations with the toys. These minigames are heavily supported by sound feedback which helps the children and reinforces the visual information on the screen.

Resulting from some of the safety concerns noted in the usability test, some improvements to the tabletop configuration are still to be made: the table should be closed with the camera and the light attached inside the table, so that children can hit and move the table with no consequence. Also, some space should be left free at the bottom of the table so that the child can be close to the table and play comfortably. These improvements would lead to a "child proof" design. At the same time, we are working on a "plug-and-play" installation. These two achievements will be crucial for a formal evaluation session with a relevant number of children which will be performed in the next future.

At the moment, the toys are passive elements. In the future, they could be upgraded into active objects, i.e.: autonomous moveable toys, illuminating objects, small displays, etc. This will open up new ways to output information and will enrich the tangible experience.

On the other hand, the tabletop prototype is versatile enough to be open to other kinds of applications suited for different educational levels. Educational applications in mathematics or physics could be designed, and there, a more complex behavior of the autonomous pedagogical agent would be needed.

\section{ACKNOWLEDGMENTS}

This work has been partly financed by the Spanish "Dirección General de Investigación", contract number N $N^{\circ}$ TIN2007-63025 and by the Aragon Government through the Cooperation Projects between University and Secondary Education Departments (2008-2009) and the IAF N $2008 / 0574$ and CyT №2008/0486 agreements

We thank Enrique Garcia Pascual and his pedagogy students from Education Sciences Department of Zaragoza University, for supporting us with the pedagogical research of this work.

We are grateful to the parents that let their children play with our tabletop. And especially, we thank the children themselves for having fun with it: Diego, Sofia, Juan and Paula.

\section{REFERENCES}

[1] Alibali and diRusso, 1999. The function of gesture in learning to count: More than keeping track. Cognitive Development. v14. 37-56.
[2] Baldassarri S., Cerezo E., Serón F., 2008. Maxine: A platform for embodied animated agents. Computer \& Graphics. ISSN: 0097-8493. Vol. 32 (4), pp.430-437. August 2008.

[3] Bencina, R. and Kaltenbrunner, M. 2005. The Design and Evolution of Fiducials for the reacTIVision System, Proceedings of the Third International Conference on Generative Systems in the Electronic Arts (Third Iteration), Melbourne, pp. $97-106$.

[4] Bers, M. U. and Cassell, J. 1998. Interactive Storytelling Systems for Children: Using Technology to Explore Language and Identity. Journal of Interactive Learning Research 9(2) 183-215. 1998

[5] Bickmore, T. and Schulman, D. 2007. Practical approaches to comforting users with relational agents. In CHI '07 Extended Abstracts on Human Factors in Computing Systems

[6] Bohn, J. 2004. The Smart Jigsaw Puzzle Assistant: Using RFID Technology for Building Augmented Real-World Games. Workshop on Gaming Applications in Pervasive Computing Environments at Pervasive 2004

[7] Burnett, Alice. 1962. "Montessori Education Today and Yesterday." The Elementary School Journal 63 (1962): 7177.

[8] CAL3D. http://cal3d.sourceforge.net

[9] Cassell, J. and Ryokai, K. 2001. "Making Space for Voice: Technologies to Support Children's Fantasy and Storytelling." Personal Technologies 5(3): 203-224.

[10] Chao L. L., J. V. Haxby and A. Martin, Attribute-based neural substrates in posterior temporal cortex for perceiving and knowing about objects. Nature Neurosci. (1999), pp. 913-919.

[11] Conati, C. and Zhao, X. 2004. Building and evaluating an intelligent pedagogical agent to improve the effectiveness of an educational game. In Proceedings of the 9th international Conference on intelligent User interfaces, 2004, 6-13.

[12] Druin, A., L. Hanna, et al. 1999. The Design of Children's Technology, Moran Kaufmann Publishers, Inc.

[13] Fontijn, W. and Hoonhout, J. 2007. Functional Fun with Tangible User Interfaces. In Proceedings of the the First IEEE international Workshop on Digital Game and intelligent Toy Enhanced Learning.

[14] Fontijn, W, and Mendels, P. 2005. StoryToy the interactive storytelling toy. In The Second International Workshop on Gaming Applications in Pervasive Computing Environments at Pervasive 2005.

[15] Gallahue, D. L. 1989. Understanding Motor Development: Infants, Children, Adolescents (2nd ed.). Indianapolis, Indiana: Benchmark Press.

[16] Gesell, Arnold, Francis Ilg, Louis Bates Ames, and Glenna Bullis. 1977. The Child from Five to Ten. New York: Harper and Row, 1977.

[17] Ishii, H. and Ullmer, B. 1997. Tangible bits: towards seamless interfaces between people, bits and atoms. In Proceedings of the SIGCHI Conference on Human Factors in Computing Systems.

[18] Johnson, M. P., Wilson, A., Blumberg, B., Kline, C., and Bobick, A. 1999. Sympathetic interfaces: using a plush toy to direct synthetic characters. In Proceedings of the 
SIGCHI Conference on Human Factors in Computing Systems.

[19] Lester, J. C., Stone, B. A., and Stelling, G. D. 1999. Lifelike Pedagogical Agents for Mixed-initiative Problem Solving in Constructivist Learning Environments. User Modeling and User-Adapted Interaction 9, 1-2 (Jan. 1999), $1-44$.

[20] Malik, S., McDonald, C., and Roth, G. 2002. Hand Tracking for Interactive Pattern-Based Augmented Reality. In Proceedings of the 1st international Symposium on Mixed and Augmented Reality .Symposium on Mixed and Augmented Reality.

[21] Mandryk, R.L., Maranan, D. S., and Inkpen, K.M. 2002. False prophets: Exploring hybrid board/video games. In Extended Abstracts of the Conference on Human Factors in Computing Systems. 640-641.

[22] Mansor, E.I.; De Angeli, A.; De Bruijn, O. 2008. Little fingers on the tabletop: A usability evaluation in the kindergarten. Horizontal Interactive Human Computer Systems, 2008. TABLETOP 2008.

[23] OpenAL++. http://alpp.sourceforge.net

[24] OpenSceneGraph. http://www.openscenegraph.org

[25] Piaget, J. 1936/1952. The Origins of Intelligence in Children. International Universities Press, New York.

[26] Piper, A. M., O'Brien, E., Morris, M. R., and Winograd, T. 2006. SIDES: a cooperative tabletop computer game for social skills development. In Proceedings of the 2006 20th Anniversary Conference on Computer Supported Cooperative Work
[27] Rizzo A, Marti P, Decortis F, Moderini C. The POGO story world. In: Hollnagel E (ed). Handbook of Cognitive Task Design. Laurence Erlbaum, London 2001.

[28] Ryokai, K., Marti, S., and Ishii, H. 2007. I/O brush: beyond static collages. In CHI '07 Extended Abstracts on Human Factors in Computing Systems

[29] Scarlatos, L. L. 2002. TICLE: using multimedia multimodal guidance to enhance learning. Inf. Sci. Inf. Comput. Sci. 140, 1 (Jan. 2002), 85-103.

[30] Soloway, E. and Bielaczyc, K. 1994. Interactive learning environments: where they've come from and where they're going. In Conference Companion on Human Factors in Computing Systems.

[31] Tapscott, D. 1997 Growing Up Digital: the Rise of the Net Generation. McGraw-Hill, Inc.

[32] Wellner, P. Interacting with Paper on the Digital Desk. Comunication of the ACM/vol 36/n.7, July 1993.

[33] Wertsch, J. V. (1985). Vygotsky and the Social Formation of Mind, Harvard University Press, Cambridge, Mass., and London.

[34] Zuckerman, O., Arida, S. and Resnick, M. 2005 , Extending tangible interfaces for education: Digital Montessori inspired manipulatives. In Proc. of CHI '05, ACM Press, 859-868. 